\title{
Rheological and Curing Behavior of a Newly Developed, Medium Viscous Acrylic Bone Cement
}

\author{
Stefan Deusser, ${ }^{1}$ Christoph Sattig, ${ }^{1}$ and Andreas Boger ${ }^{2}$ \\ ${ }^{1}$ Research \& Development, aap Biomaterials, 64807 Dieburg, Germany \\ ${ }^{2} \mathrm{R} \& \mathrm{D}$ Biomaterials, Synthes GmbH, 4436 Oberdorf, Switzerland \\ Correspondence should be addressed to Stefan Deusser, s.deusser@aap.de
}

Received 15 July 2011; Accepted 9 August 2011

Academic Editors: J. Provis and H. Yoshihara

Copyright (C 2011 Stefan Deusser et al. This is an open access article distributed under the Creative Commons Attribution License, which permits unrestricted use, distribution, and reproduction in any medium, provided the original work is properly cited.

\begin{abstract}
Percutaneous vertebroplasty, comprising an injection of polymethylmethacrylate (PMMA) bone cement into vertebral bodies, is a practical procedure for stabilization of osteoporotic compression fractures and other weakening lesions. Cement leakage is considered to be the major complication. The viscosity plays a key role in this context. At high viscosity, the risk of leakage is reduced; however, injection forces are highly increased, handling time is reduced. The purpose of the study was to investigate the rheological, handling and hardening behaviour of a newly developed medium viscous bone cement at different temperatures and by simulation of a temperature shift to body-temperature. The presented data give an impression on the injectability of the cement using different sized needles. It could be concluded, that the medium viscous cement shows an adequate working time for a broad temperature range and an acceptable hardening time of around $11 \mathrm{~min}$ after immersing the cement into a $37^{\circ} \mathrm{C}$ environment.
\end{abstract}

\section{Introduction}

The technique of percutaneous vertebroplasty dates back to Galibert and Déramond, who, as early as the end of the 1980s in France used the injection of PMMA cement into the vertebral bodies of patients with aggressive hemangioma and other tumors to produce mechanical stabilization and pain relief $[1,2]$. The use of percutaneous vertebroplasty in osteoporotic vertebral compression fractures was first described in France in 1990 [3]. The technique of percutaneous vertebroplasty began to be used in the USA at the end of the 1990s [4-6]. Generally, the injected cement does not allow any reerection of the compressed vertebra, but instead acts as a splint that strengthens the vertebra and stabilizes the fracture. This results in a significant reduction in pain and improvement in quality of life, with relatively low burdens on the healthcare system [7-9].

Though many bone cements have been established throughout the years, new materials with improved properties which afford a better appliance and increase the safety of the procedures are developed furthermore. Requirements of an ideal material for vertebral augmentation have been formulated by Heini and Berlemann [10]. The material should be injectable and easy to handle, it should show a high radiopacity, an appropriate viscosity (never too low), a persistently good viscosity, a long hardening time, a low hardening temperature, appropriate and long-lasting mechanical properties, biocompatibility, bioactivity, slow biodegradation and a low price.

Commercially available bone cements fulfill these demands only partially. Concerning an appropriate viscosity, two cements are marketed that allow immediate application after preparation. However, the application is only possible with a special, high-pressure application equipment (Conficence, DePuy Spine and VertaPlex HV, Stryker Instruments). A main drawback in using such high-pressure systems is the loss of the tactile feedback as opposed to simple syringe systems. A surgeon survey showed that the majority prefers intuitive syringe systems, which give the surgeon a direct force feedback during injection and therefore a very good tactile feeling for the procedure. The required working time mentioned by the surgeons was around $15 \mathrm{~min}$. Other cements approved for vertebroplasty (Vertecem, Synthes, Oberdorf, Switzerland; Osteopal V, HeraeusMedical, Hanau, Germany; Spineplex and VertaPlex, Stryker Instruments, Duisburg, Germany; KyphX HV-R, Medtronic, 
Tolochenaz, Switzerland) which are applicable by using simple syringe systems present a waiting time ranging from 2.5 and 10 minutes. The working time, beginning with reaching an appropriate viscosity, ranges from 4.5 to around 12 minutes. Up till now no approved cement shows a low waiting time and a long working time above 12 minutes at an ambient temperature range from $19-26^{\circ} \mathrm{C}$, without requiring high force injection systems. In order to address the reduction in waiting time, sufficient working time and the compatibility with syringe systems, the development of a new PMMA vertebroplasty cement was undertaken. The goals of that development were to achieve a high initial viscosity right after mixing, diminish waiting time and an increased working time. These properties would allow the surgeon to begin injection immediately after cement preparation without the need to wait for the cement reaching a minimum viscosity level and to continue with the procedure.

Because the ambient temperature in the operation theatre varies, the desired working time of around $15 \mathrm{~min}$ should be observable for an appropriate temperature range. Due to the radical polymerization of acrylic cement the hardening time, decreases at higher temperatures. Engineering a relative long working time for the upper border of the ambient temperature results in an extended hardening times at lower temperatures. A longer hardening time could lead to the concern that it would take too long until the cement is partly load bearing, which may hinder moving the patient from the operation site after finishing the injection. Caused by the temperature increase after injection into the vertebral body $\left(37^{\circ} \mathrm{C}\right.$ body temperature) the working and hardening time will decrease in clinical use. For economic reason it is desired to move a patient as soon as possible after cement injection is finished. Therefore the hardening time of the cement after stopping injection is important to be known.

The purpose of the study was to investigate the rheological, handling, and hardening behaviour of a newly developed medium viscous PMMA bone cement for the use in cancellous bone augmentation at different ambient conditions and during clinically relevant temperature profiles.

\section{Materials and Methods}

The cement used and characterized in the study is a newly development of an acrylic cement for the clinical application of cancellous bone augmentation (Vertecem V+ Cement Kit, Ref. 07.702.016S, LOT: 09CA53010, Synthes GmbH, Oberdorf, Switzerland).

Handling characteristics of interest are the initial viscosity, the application time, and the hardening time. The initial viscosity determines the waiting time until the material is ready for a safe injection in order to reduce the risk of cement leakage. The apparent initial viscosity of the investigated cement, when injected immediately after preparation was judged high enough, leading to a minimal leakage rate and an uniform cement filling as shown in a previous in vitro study (Wheeler et al., submitted for publication). Application time defines the time after beginning cement preparation until the time when the cement could not be manually injected through a given injection system anymore. The hardening time relates to the time after starting cement preparation until the polymerization process is almost completed, indicated by a decrease in cement temperature and a hard cured material.

Hardening behaviour of the cement mixture was characterized using rheological measurements, injection force measurements, hands-on knocking tests and investigations of the polymerization temperature. Because the ambient and cement temperature is a predominant parameter for the curing of the cement, cement hardening behaviour was investigated at different ambient and cement temperatures. Ambient temperature range applied for the testing was defined in order to cover the range $18-26^{\circ} \mathrm{C}$ given in the DIN 1946-4, 1999-03 standard.

The investigation of the polymerization temperature and setting time was performed according to the ISO 5833:2002 standard. Additionally, the reduction in hardening time of the cement subjected to $37^{\circ} \mathrm{C}$ was investigated in order to get closer to the clinical situation. For comparison reasons the later test was performed additionally with a faster hardening, regular vertebroplasty cement (Vertecem Mixing Kit, Ref. 07.702.010, Synthes GmbH, Oberdorf, Switzerland).

\section{Cement and Sample Preparation}

Because the tests were performed at different ambient conditions, all equipment which comes in contact with the cement was tempered at the respective temperature $\left( \pm 1^{\circ} \mathrm{C}\right)$ for at least 24 hours. The laboratory was left to be equilibrated to the respective temperature before starting the measurement. Room temperature was controlled by an automatically air-conditioned laboratory system throughout all testing. The humidity of the laboratory was controlled and was always higher than $40 \%$. The accuracy of the ambient temperature was $\pm 0.5^{\circ} \mathrm{C}$. The powder and monomer of the used cements were mixed according to the manufacturer's instruction. The stop watch was started when the monomer was added to the powder recording the time after start of mixing.

\section{Rheological Measurements at Different Ambient Temperatures}

To determine qualitatively the polymerization kinetic of the hardening, and the initial viscosity quantitatively, a rheological investigation was performed to derive the cement viscosity as a function of time after starting the cement preparation. For the viscosity measurements, $3 \mathrm{~mL}$ of the prepared cement was placed in a rotational rheometer (Viscosafe Viscometer, Anton Paar, Graz, Austria, SN 80215110 REF 03.702.010) according to the method described in a previous study [11]. Real viscosity was recorded every $5 \mathrm{~s}$ directly to a PC using the corresponding software (RHEOPLUS/32 Multi 128 V2.66, Anton Paar, Graz, Austria). The rheometer was set to operate at an oscillatory frequency of $1 \mathrm{~Hz}$ and a maximum torque of $3 \mathrm{mNm}$. Viscosity measurements were started $2 \mathrm{~min}$ after start of mixing. The initial viscosity 
was determined as the minimal viscosity measured during the rheological data acquisition. Six trials were performed at each ambient temperature $\left(19,21,23,25\right.$ and $\left.27^{\circ} \mathrm{C}\right)$. Initial viscosities for the various ambient temperatures are presented as means and standard deviations (mean $\pm \mathrm{SD}$ ). Cement viscosity as a function of time after start mixing is presented with one representative measurement for each ambient temperature.

\section{Injection Force Measurements at Different Ambient Temperatures}

Injection forces as a function of time after the start of cement preparation were measured as applied on a $1 \mathrm{~mL}$ syringe and required to inject the cement through a vertebroplasty needle. In order to investigate the application time for different injection setups the $1 \mathrm{~mL}$ syringes were attached to differentsized vertebroplasty side opening needles (Vertebroplasty Injection Kits: 8 Ga, 10 Ga, 12 Ga, Art. No. 20007 512; 10 Ga, Art. No. 20009 768; 12 Ga, Art. No. 20009 769; Synthes $\mathrm{GmbH}$, Oberdorf, Switzerland). The side opening needles present an inner diameter of $3.2,2.4$, and $1.7 \mathrm{~mm}$, and a length of 176,155 and $155 \mathrm{~mm}$ for the named $8 \mathrm{Ga}, 10 \mathrm{Ga}$, and $12 \mathrm{Ga}$ needles, respectively. The needles were mounted on an Instron 3366 universal testing machine (Instron, SN.: $3366 \mathrm{~K} 1840$, Canton, USA) equipped with a $5.0 \mathrm{kN}$ load cell to measure injection forces. Injection was performed into air. Sampling rate of the injection force was $10 \mathrm{~Hz}$ (control and analysis software: Bluehill 2, Instron, Canton, USA).

The injection test was performed as follows. After cement preparation ten $1 \mathrm{~mL}$ syringes (Viscosafe Injection Kit, Ref. 07.702.210, Synthes GmbH, Oberdorf, Switzerland) and the side opening needle were filled with the bone cement using a coupling adapter. The first $1 \mathrm{~mL}$ syringe was mounted on the prefilled side opening needle. Injection was started with a delay of $5 \mathrm{~min}$ and $10 \mathrm{~min}$ after start mixing for the tests performed at ambient temperature of $23,25,27^{\circ} \mathrm{C}$, and 19 , $21^{\circ} \mathrm{C}$, respectively. The contents of each of the syringes were injected in 2 steps, each one running for $40 \mathrm{sec}$ (volume flow rate $0.75 \mathrm{~mL} / \mathrm{min}$ ) with a $10 \mathrm{sec}$ break between the two steps. The time to change syringes was 50 seconds on average [12]. After the injection of the first syringe the other syringes follow until an injection force of $150 \mathrm{~N}$ was required due to cement polymerization. The flow rate was chosen at the lowest limit of average clinical measurements [13]. In a previous unpublished study using an instrumented syringe holder, a manual force of $90 \mathrm{~N}$ could be defined as a reasonable limit for a controlled one-hand injection. Therefore the application time was defined by the time after start mixing reaching an injection force of $90 \mathrm{~N}$ for the used setup. The setup parameters were the used needle size $(8 \mathrm{Ga}$, $10 \mathrm{Ga}$, and $12 \mathrm{Ga})$ and the ambient temperature $(19,21,23$, 25 , and $27^{\circ} \mathrm{C}$ ). Six trials were performed using an $8 \mathrm{Ga}$ needle at each temperature. The application time measurements using the $10 \mathrm{Ga}$ and $12 \mathrm{Ga}$ needles were only performed at an ambient temperature of $23^{\circ} \mathrm{C}(n=6)$. The injection force as a function of time after start mixing is presented with one representative measurement for each needle size at $23^{\circ} \mathrm{C}$. Application times are presented as mean $\pm \mathrm{SD}$ for the ambient temperatures and needle setups investigated.

\section{Hardening Time at Different Ambient Temperatures}

The hardening time of the cement was determined by a hands-on knocking test. Therefore, approximately $4 \mathrm{~mL}$ of the prepared bone cement was manually formed to a walnut-sized ball and placed on the table. For performing the test the cement walnut was knocked on the table after different time intervals. At a certain time the sample began to get warmer and the consistency got harder. At this stage of polymerization the test was performed every $10 \mathrm{~s}$. The hardening time is defined by the earliest time after start mixing when the knocking sound is clear and glassy. The hands-on knocking test as introduced by Kühn [14] is an easy performable and good repeatable investigation of cement hardening without the need of any special test equipment. The cement is completely hardened if it sounds clear and glassy when a cement ball is knocked on a hard surface. This test was performed in six trials at different ambient temperatures $\left(19,21,23,25\right.$, and $\left.27^{\circ} \mathrm{C}\right)$. Hardening times are presented as mean \pm SD for the investigated ambient temperatures.

\section{Rheological Measurements During a Temperature Switch from $23^{\circ} \mathrm{C}$ to $37^{\circ} \mathrm{C}$}

In the former tests the hardening time was determined to be as long as 32 minutes, this time was believed to shorten significantly after temperature transition to body temperature. Therefore the influence of a temperature shift from room to body temperature on the hardening behaviour of the cement was investigated. The purpose of this experimental part was to show the alteration of the cement viscosity as a function of time after start mixing applying a temperature profile simulating the transition from room to body temperature as in clinical application. The setup and method used were the same as for the previous rheological investigation using additional heating equipment to apply the temperature profile to the measurement cell. Later setup is described in detail in a previous study [11]. In order to simulate the cement injection at different cement curing states, the temperature of the viscosity measurement cell was raised from $23^{\circ} \mathrm{C}$ to $37^{\circ} \mathrm{C}$ at a real viscosity of 120,360 , 600 , and $1200 \mathrm{~Pa}^{*}$ s. The described method was performed in triplicates resulting in twelve runs for this investigation. Cement viscosities as a function of time, depending on the different switch conditions, are presented in a representative manner. The acceleration in increasing viscosity due to the temperature switch to $37^{\circ} \mathrm{C}$ is given by the averaged time periods from the performed transition until a cement viscosity of $2000 \mathrm{~Pa}^{*}$ s was reached. The mentioned time periods are quantitatively presented in percentage to the corresponding time period received from the measurements of the cement viscosity as a function of time after start mixing at $23^{\circ} \mathrm{C}$. 


\section{Hardening Time after a Temperature Switch from $23^{\circ} \mathrm{C}$ to $37^{\circ} \mathrm{C}$}

From a clinical prospective it is important to know how long the waiting time after finishing cement injection must be until a safe movement of the patient is possible. Therefore the hardening time as already mentioned previously was investigated when the cement is applied to $37^{\circ} \mathrm{C}$. To investigate this hardening behaviour, cement samples of $3.5 \mathrm{~mL}$ and $7 \mathrm{~mL}$ contained in a cropped finger of nitril gloves were inserted $4 \mathrm{~min}$ after start of mixing in a $37^{\circ} \mathrm{C}$ water bath (Lauda, Ecoline RE 306, LAUDA GMBH \& CO. KG, LaudaKoenigshofen, Germany). Supported cement volumes reflect typical volumes used in uni- or bipedicular augmentation procedures. The container of the cement samples was closed using cable binders and manually formed to obtain a nearly spherical shape. To determine the hardening time of those samples, the already described knocking test was started at around $8 \mathrm{~min}$ after inserting the sample in the bath. For the test, the sample was shortly touched with the fingers inside the water bath every $20 \mathrm{~s}$ until the cement did not appear soft anymore. Afterwards the cement sample was taken out of the water repeatedly for several seconds to perform the hands-on knocking test every 20 s. If the knocking sound was clear and glassy the hardening time was recorded from the stop watch. Enabling a comparison of the results to commonly used regular vertebroplasty cement another acrylic cement (Vertecem Mixing Kit, Ref. 07.702.010, Synthes GmbH, Oberdorf, Switzerland) was supported for the same test. The testing protocol for the added material group was the same, except that the waiting time before putting the cement samples in $37^{\circ} \mathrm{C}$ environment was at the time when the cement reaches a viscosity of $50 \mathrm{~Pa}^{*} \mathrm{~s}$ (approximately $7-8 \mathrm{~min}$ ) as earliest recommended injection start by the supplier. Each cement volume was investigated in five identical runs. The reduction in hardening due to the temperature switch to $37^{\circ} \mathrm{C}$ is given by the averaged hardening time periods from immersing the samples into the water bath until the hardening time was reached. The mentioned time periods are quantitatively presented in percentage to the corresponding time period received from the measurements of the hardening time at $23^{\circ} \mathrm{C}$. Additionally, the hardening time periods received from the switch experiments and the one at $23^{\circ} \mathrm{C}$ are presented as mean $\pm \mathrm{SD}$.

\section{Polymerization Temperature and Setting Time (ISO 5833:2002)}

The relative long curing time of the newly developed vertebroplasty cement (Vertecem V+ Cement Kit, Ref. 07.702.016S, Synthes GmbH, Oberdorf, Switzerland) might logically result in a reduced maximum polymerization temperature, because the heat release rate $(\mathrm{W} / \mathrm{s})$ is lower in comparison to other PMMA cements which harden faster. Therefore the maximum polymerization temperature and the setting time at $23^{\circ} \mathrm{C}$ of the presented cement was investigated and compared to the values received [15] from a regular vertebroplasty cement (Vertecem Mixing Kit, Ref.

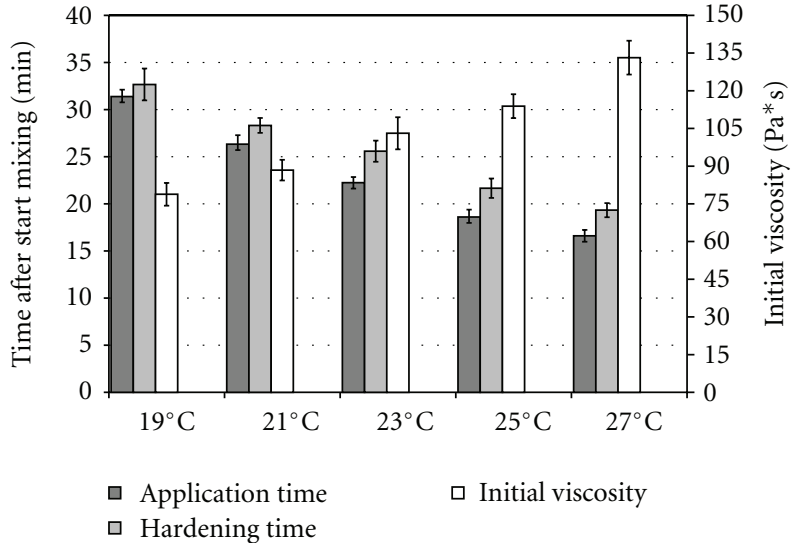

Figure 1: Initial viscosity, application time ( $8 \mathrm{Ga})$, and hardening time at different ambient temperatures for Vertecem $\mathrm{V}+$.

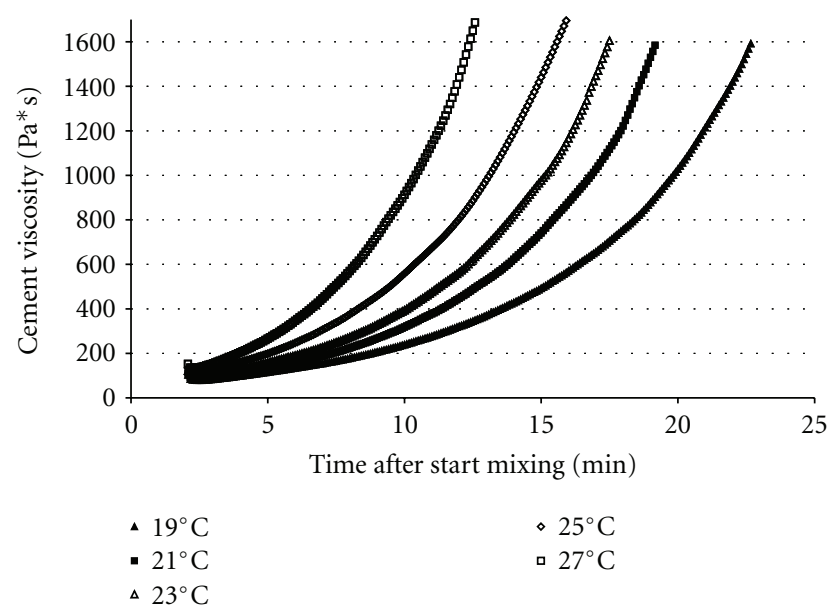

Figure 2: Representative hardening curves showing the cement viscosity as function of time after start mixing of Vertecem $\mathrm{V}+$ cement for different temperatures investigated.

07.702.010, Synthes GmbH, Oberdorf, Switzerland) which hardens faster. Polymerization temperature and setting time was determined according to the method described in the ISO 5833:2002 standard using the devices described in Boger et al. [15]. Statistical differences of both parameters maximum temperature and setting time were compared using a nonparametric $t$-test for the two cements investigated. Both parameters are presented as mean \pm SD for both cements.

\section{Results}

Initial viscosity increased at higher investigation temperature. At a room temperature of $19^{\circ} \mathrm{C}$ the initial viscosity of Vertecem $\mathrm{V}+$ was $79 \mathrm{~Pa}^{*} \mathrm{~s}$ (mean) and increased to $133 \mathrm{~Pa}^{*} \mathrm{~s}$ for an investigation temperature of $27^{\circ} \mathrm{C}$. More in detail the initial viscosity data received are presented in Figure 1. Qualitatively the polymerization kinetic at different ambient temperatures showing acceleration with higher temperatures is shown in Figure 2, presenting the cement viscosity as function of time after start mixing. 


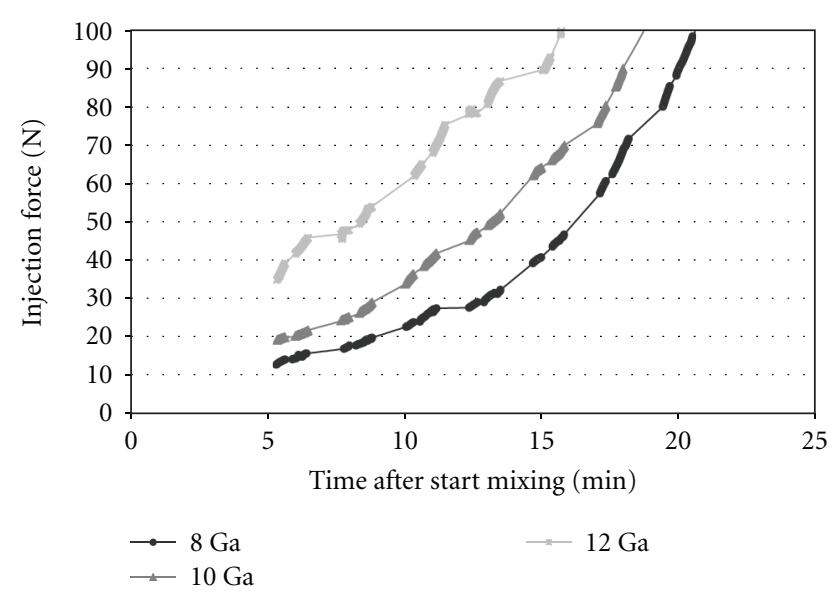

Figure 3: Injection force for Vertecem $\mathrm{V}+$ as function of time after start mixing using $8 \mathrm{Ga}, 10 \mathrm{Ga}$, and $12 \mathrm{Ga}$ needle and a $1 \mathrm{~mL}$ syringe at ambient temperature of $23^{\circ} \mathrm{C}$.

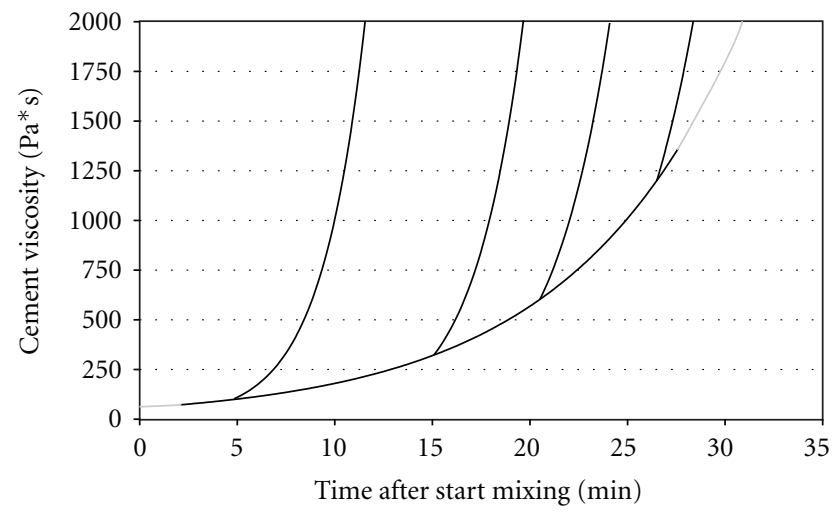

Figure 4: Averaged cement viscosity of Vertecem V+ as function of time after start mixing at $23^{\circ} \mathrm{C}$ (lower line) and with a temperature shift to $37^{\circ} \mathrm{C}$ at a given viscosity level (attached upturn curves).

Figure 3 demonstrates the representative injection force curves using $8 \mathrm{Ga}, 10 \mathrm{Ga}$, and $12 \mathrm{Ga}$ needle at ambient temperature of $23^{\circ} \mathrm{C}$.

Application time (mean $\pm \mathrm{SD}$ ) at $23^{\circ} \mathrm{C}$ was $20 \pm 1 \mathrm{~min}$, $18 \pm 0.5 \mathrm{~min}$, and $14 \pm 0.5 \mathrm{~min}$ using the $8 \mathrm{Ga}, 10 \mathrm{Ga}$, and $12 \mathrm{Ga}$ needles, respectively. Application times decreased as expected at higher investigated ambient temperature. Application time using the $8 \mathrm{Ga}$ needle decreased from $32 \mathrm{~min}$ to $17 \mathrm{~min}$ for ambient temperatures of $19-27^{\circ} \mathrm{C}$, respectively (Figure 1).

Hardening time decreased at higher ambient temperature. Hardening time decreased from around $33 \mathrm{~min}$ to $19 \mathrm{~min}$ for ambient temperatures of $19-27^{\circ} \mathrm{C}$, respectively (Figure 1).

Figure 4 shows the averaged cement viscosity as a function of time after start mixing with a temperature shift to $37^{\circ} \mathrm{C}$ at a given viscosity level.

After temperature shift a cement viscosity of $2000 \mathrm{~Pa}^{*} \mathrm{~s}$ was reached within 6.7-2.4 minutes. In comparison to the hardening behaviour at $23^{\circ} \mathrm{C}$, these values present a reduction in handling time of $74-43 \%$ if the temperature switch was applied at $120-1200 \mathrm{~Pa}^{*}$ s, respectively (Table 1).
As presented in Figure 5 the hardening time of the newly developed cement (Vertecem $\mathrm{V}+$ ) is reduced to around $14.4 \pm 0.4$ min (mean $\pm \mathrm{SD}, 7 \mathrm{~mL}$ ) due to temperature shift to $37^{\circ} \mathrm{C}$ in comparison to the hardening time of $25.5 \pm 1.5 \mathrm{~min}$ at $23^{\circ} \mathrm{C}$. The relative small standard deviations demonstrate the mentioned high reliability of the simple hands-on knocking test.

Hardening time of the regular cement (Vertecem) with a temperature shift at a viscosity of $50 \mathrm{~Pa}^{*} \mathrm{~s}(7.4 \mathrm{~min}$ after start mixing) was observed at $15.4 \pm 0.4 \mathrm{~min}(7 \mathrm{~mL})$ after start mixing. Differences between the two cement volumes supported were not significantly different $(P=0.89)$ for both investigated cements. The hardening time, when a temperature shift to $37^{\circ} \mathrm{C}$ was performed, of the newly developed cement (Vertecem $\mathrm{V}+$ ) was significantly shorter compared with the regular cement (Vertecem) $(P<0.5)$.

The setting time of the newly developed cement (Vertecem $\mathrm{V}+$ ) and regular cement (Vertecem) as described by ISO 5833:2002, was $28.3 \pm 0.7 \mathrm{~min}$ and $29.3 \pm 0.5 \mathrm{~min}$, respectively. The maximum polymerization temperature of the new cement (Vertecem $\mathrm{V}+$ ) and the regular one (Vertecem) as described by ISO 5833:2002, was $53.5 \pm 0.5^{\circ} \mathrm{C}$ and $71.6 \pm 3.8^{\circ} \mathrm{C}$, respectively. Statistical difference could only be obtained for the polymerization temperature, showing a lower polymerization temperature for the newly developed cement (Vertecem $\mathrm{V}+$ ) in comparison to the regular cement (Vertecem; $P<0.05$ ).

\section{Discussion}

The presented study investigated the rheological and hardening behaviour of newly developed cement for the use in cancellous bone augmentation at different ambient conditions and during clinical relevant temperature profiles.

Clinical observations and investigations [11] showed less to no leakage using commercial vertebroplasty cements (Vertecem, Synthes GmbH; Vertebroplastic, J\&J DePuy Inc.) at a start injection viscosity of around $50 \mathrm{~Pa}^{*} \mathrm{~s}$. The lowest initial viscosity of $79 \mathrm{~Pa}^{*} \mathrm{~s}$ (mean) measured herein at $19^{\circ} \mathrm{C}$ was already above the mentioned value reported as safe injection viscosity in clinical use. Following from higher initial viscosity the risk of cement extravasation during application is reduced and the force necessary for the application of the cement rises. As shown in vitro, Vertecem V+ presents an initial viscosity level leading to a low leakage rate and an uniform cement filling, which should allow cement injection direct after preparation (data not published). The application time given by a required injection force of $90 \mathrm{~N}$ using an $8 \mathrm{Ga}$ needle and a $1 \mathrm{~mL}$ syringe corresponds to a cement viscosity of around $7000 \mathrm{~Pa}^{*}$ s. The cement design also allows cement application within a sufficient time frame at high ambient temperatures of $27^{\circ} \mathrm{C}$ using hand-operated syringes.

The application time of the cement is strongly influenced by needle size (diameter and length) and ambient temperature. Increased application forces at higher ambient temperatures are caused by the higher viscosities. Similarly, the use of needles having a smaller diameter requires a higher 
TABLE 1: Averaged time periods from the performed transition until a cement viscosity of $2000 \mathrm{~Pa}^{*} \mathrm{~s}$ was reached, corresponding time period without temperature switch applied, and resulting reduction in percentage using the Vertecem V+ cement.

\begin{tabular}{lccc}
\hline $\begin{array}{l}* \text { Cement viscosity where the } \\
\text { referred time period start/Pa*s }\end{array}$ & $\begin{array}{c}\text { Time period to reach } 2000 \mathrm{~Pa}^{*} \mathrm{~s} \\
\text { after } * \text { at } 23^{\circ} \mathrm{C} \\
\text { Mean } \pm \mathrm{SD} / \mathrm{min}\end{array}$ & $\begin{array}{c}\text { Time period to reach } 2000 \mathrm{~Pa}^{*} \mathrm{~s} \\
\text { after shift to } 37^{\circ} \mathrm{C} \text { at } * \\
\text { Mean } \pm \mathrm{SD} / \mathrm{min}\end{array}$ & $\begin{array}{c}\text { Reduction on average in } \% \text { of the } \\
\text { time periods from } 23^{\circ} \mathrm{C} \text { curve }\end{array}$ \\
\hline 120 & $25.8 \pm 2.3$ & $6.7 \pm 2.0$ & 74 \\
360 & $15.9 \pm 2.0$ & $4.8 \pm 1.3$ & 70 \\
600 & $10.3 \pm 1.8$ & $3.9 \pm 0.3$ & 62 \\
1200 & $4.2 \pm 1.5$ & $2.4 \pm 0.5$ & 43 \\
\hline
\end{tabular}

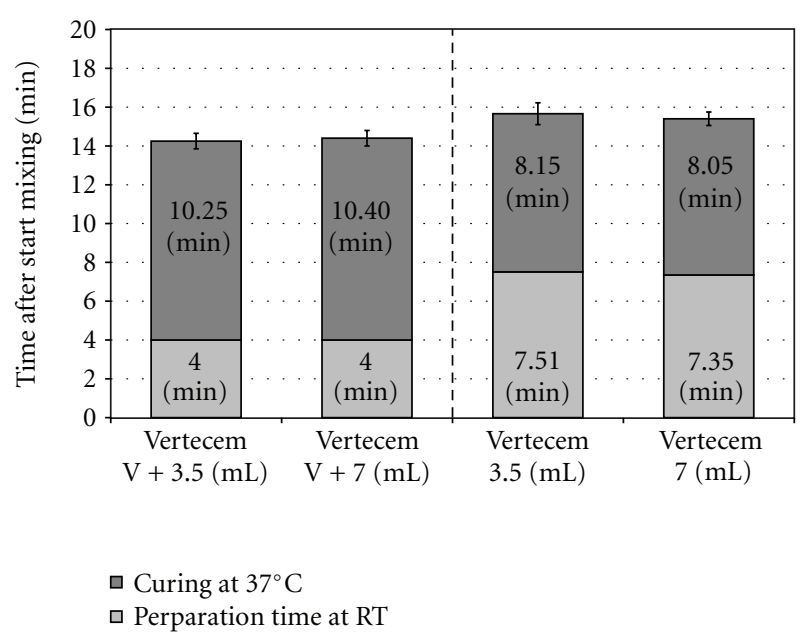

Figure 5: Averaged hardening time of Vertecem V+ and Vertecem after mixing at $23^{\circ} \mathrm{C}$ and with a temperature shift to $37^{\circ} \mathrm{C}$ after preparation.

application force according to the law of Hagen resulting in a reduced application time. The long application phase provided by the newly developed cement results in a slightly extended hardening time of the cement. However, it has to be considered that the setting process is significantly accelerated when the cement is implanted, as shown in the temperature shift experiments.

To characterize the cement behaviour under clinical conditions the viscosity and the hardening time were investigated after the cement was prepared at $23^{\circ} \mathrm{C}$ and subsequently shift to $37^{\circ} \mathrm{C}$. The temperature shift was performed by tempering the viscosity measurement chamber. Simultaneous measurement of the temperature on the viscosity cell revealed that the temperature inside the cup reached $36.8^{\circ} \mathrm{C}$ after a period of $50-60 \mathrm{~s}$ which exceeds the temperature transition time.

When using commercial vertebroplasty bone cements it is necessary to wait until an adequate viscosity has been reached before injection, in order to reduce the risk of cement extravasation.

These facts were taken as a basis for the definition of the time point of the temperature shift. Comparing the hardening time of the new cement formulation (Vertecem $\mathrm{V}+$ ) with a commercially vertebroplasty bone cement (Vertecem) after the temperature shift, the Vertecem $\mathrm{V}+$ presented a hardening, which was on average 1 min longer. Hardening time of Vertecem $\mathrm{V}+$ is located between 10 and 11 minutes after injection in $37^{\circ} \mathrm{C}$ environment. The commercial cement (Vertecem) needs 2 min less to reach similar hardness after immersion into $37^{\circ} \mathrm{C}$, but takes much longer in preparation till it reaches the required $50 \mathrm{~Pa}^{*} \mathrm{~s}$ for a safe injection (around $7.5 \mathrm{~min})$.

In general Vertecem $\mathrm{V}+$ shows a similar curing behaviour/hardening time compared to Vertecem, after injection in $37^{\circ} \mathrm{C}$ environment. The in vivo hardening behaviour will also be dependent on the capacity of adjacent tissue to conduct (by thermal diffusion at the cement-tissue interface) and convert (by the circulation of blood and cerebrospinal fluid) this energy to surrounding tissue [16]. The test setup shows a very good heat dissipation which is probably higher than the heat dissipation inside of a good vesiculated vertebral body. Thus the in vivo hardening time might be between the values measured at ambient temperature and the temperature shift results. Therefore it could be derived that a waiting time before moving the patient of around $15 \mathrm{~min}$ after finalizing the cement injection could be recommended to the practitioner as a safe time point. As reported the hardening time is reduced tremendously when the cement is placed at $37^{\circ} \mathrm{C}$. Thus the injectability limit is reached earlier in comparison to lower working temperatures.

A potential side effect of acrylic cements is heat damage to adjacent tissues and bones that can lead to necrosis [17-19]. Nevertheless, to date no vertebro- or kyphoplasty procedure has been described in which such noteworthy side effects could have been attributed to thermal damage [20]. The ISO 5833:2002 standard applicable to PMMA bone cements requires a temperature of less than $90^{\circ} \mathrm{C}$ during curing of the bone cement. Thermal necrosis of bone is induced at temperatures exceeding $50^{\circ} \mathrm{C}$ for more than one minute [21-23]. The maximum tolerable temperature load for nerve tissue is quoted as $45^{\circ} \mathrm{C}$ for $30 \mathrm{~min}$, or comparable doses of thermal energy (e.g., $42^{\circ} \mathrm{C}$ for $60 \mathrm{~min}$ ) [24-26]. Experiments performed in live animals showed a reduced average maximum temperature due to the convection of heat [16]. The setting time of the newly developed cement (Vertecem V+) and the cement (Vertecem) as described by ISO 5833:2002, was comparable. The maximum polymerization temperature measured for the newly developed cement (Vertecem V+) was $53.5 \pm 0.5^{\circ} \mathrm{C}$. However, the results of the ISO 5833:2002 maximum temperature investigation are not adequate for giving a definite statement about 
a possible necrosis caused by heat damage in succession of the exothermic curing reaction. The amount of cement used, the temperature of the surrounding tissue as well as the heat convection is not recognized. These factors influence the maximum temperature. Anyway, a lower maximum temperature indicates a lower risk of thermal damage within clinical usage.

\section{Conclusion}

The newly developed bone cement presented herein shows a medium viscosity directly after preparation, which allows an immediate start of application. Anyway, the cement is injectable for at least $15 \mathrm{~min}$ at an ambient temperature lower than $27^{\circ} \mathrm{C}$ using a usual low volume syringe. The handling and hardening times are enormously shortened by a shift to body temperature. An acceptable hardening time of around $10 \mathrm{~min}$ after immersion the cement into $37^{\circ} \mathrm{C}$ could be shown for the Vertecem $\mathrm{V}+$. It could be derived that a waiting time before moving the patient of around $15 \mathrm{~min}$ after finalizing the cement injection could be recommended to the practitioner as a safe time point.

\section{References}

[1] P. Galibert, H. Deramond, P. Rosat, and D. Le Gars, "Preliminary note on the treatment of vertebral angioma by percutaneous acrylic vertebroplasty," Neurochirurgie, vol. 33, no. 2, pp. 166-168, 1987.

[2] P. Kaemmerlen, P. Thiesse, H. Bouvard, P. Biron, F. Mornex, and P. Jonas, "Vertébroplastie percutanée dans le traitement des métastases. Technique et résultats," Journal de Radiologie, vol. 70, no. 10, pp. 557-562, 1989.

[3] P. Galibert and H. Déramond, "La vertébroplastie acrylique percutanée comme traitement des angiomes vertébraux et des affections dolorigènes et fragilisantes du rachis," Chirurgie Paris, vol. 116, no. 3, pp. 326-335, 1990.

[4] M. P. G. Bostrom and J. M. Lane, "Future directions: augmentation of osteoporotic vertebral bodies," Spine, vol. 22, no. $24,1997$.

[5] M. E. Jensen and J. E. Dion, "Vertebroplasty relieves osteoporosis pain," Diagnostic Imaging, vol. 19, no. 9, pp. 68-72, 1997.

[6] M. E. Jensen, A. J. Evans, J. M. Mathis, D. F. Kallmes, H. J. Cloft, and J. E. Dion, "Percutaneous polymethylmethacrylate vertebroplasty in the treatment of osteoporotic vertebral body compression fractures: technical aspects," American Journal of Neuroradiology, vol. 18, no. 10, pp. 1897-1904, 1997.

[7] A. Fisher, "Percutaneous vertebroplasty: a bone cement procedure for spinal pain relief," Issues in Emerging Health Technologies, no. 31, pp. 1-4, 2002.

[8] J. M. Mathis, A. O. Ortiz, and G. H. Zoarski, "Vertebroplasty versus kyphoplasty: a comparison and contrast," American Journal of Neuroradiology, vol. 25, no. 5, pp. 840-845, 2004.

[9] J. K. McGraw, J. Cardella, J. D. Barr et al., "Society of interventional radiology quality improvement guidelines for percutaneous vertebroplasty," Journal of Vascular and Interventional Radiology, vol. 14, no. 7, pp. 827-831, 2003.

[10] P. F. Heini, U. Berlemann, M. Kaufmann, K. Lippuner, C. Fankhauser, and P. Van Landuyt, "Augmentation of mechanical properties in osteoporotic vertebral bones-a biomechanical investigation of vertebroplasty efficacy with different bone cements," European Spine Journal, vol. 10, no. 2, pp. 164-171, 2001.

[11] A. Boger, K. D. Wheeler, B. Schenk, and P. F. Heini, "Clinical investigations of polymethylmethacrylate cement viscosity during vertebroplasty and related in vitro measurements," European Spine Journal, vol. 18, no. 9, pp. 1272-1278, 2009.

[12] A. Gisep and A. Boger, "Injection biomechanics of in vitro simulated vertebroplasty - Correlation of injection force and cement viscosity," Bio-Medical Materials and Engineering, vol. 19, no. 6, pp. 415-420, 2009.

[13] J. Krebs, S. J. Ferguson, M. Bohner, G. Baroud, T. Steffen, and P. F. Heini, "Clinical measurements of cement injection pressure during vertebroplasty," Spin, vol. 30, no. 5, pp. E118122, 2005.

[14] K.-D. Kühn, Bone cements - Up-to-Date Comparison of Physical and Chemical Properties of Commercial Materials, Springer, Berlin, Germany, 2000.

[15] A. Boger, M. Bohner, P. Heini, S. Verrier, and E. Schneider, "Properties of an injectable low modulus pmma bone cement for osteoporotic bone," Journal of Biomedical Materials Research Part B, vol. 86, pp. 474-482, 2008.

[16] J. J. Verlaan, F. C. Oner, A. J. Verbout, and W. J. Dhert, "Temperature elevation after vertebroplasty with polymethylmethacrylate in the goat spine," Journal of Biomedical Materials Research Part B, vol. 67, pp. 581-585, 2003.

[17] G. Baroud, M. Samara, and T. Steffen, "Influence of mixing method on the cement temperature-mixing time history and doughing time of three acrylic cements for vertebroplasty," Journal of Biomedical Materials Research Part B, vol. 68, pp. 112-116, 2004.

[18] S. M. Belkoff and S. Molloy, "Temperature measurement during polymerization of polymethylmethacrylate cement used for vertebroplasty," Spine, vol. 28, no. 14, pp. 1555-1559, 2003.

[19] H. Deramond, N. T. Wright, and S. M. Belkoff, “Temperature elevation caused by bone cement polymerization during vertebroplasty," Bone, vol. 25, no. 1, pp. 17S-21S, 1999.

[20] J. M. Spivak and M. G. Johnson, "Percutaneous treatment of vertebral body pathology," The Journal of the American Academy of Orthopaedic Surgeons, vol. 13, no. 1, pp. 6-17, 2005.

[21] R. A. Eriksson, T. Albrektsson, and B. Magnusson, "Assessment of bone viability after heat trauma. A histological, histochemical and vital microscopic study in the rabbit," Scandinavian Journal of Plastic and Reconstructive Surgery, vol. 18, pp. 261-268, 1984.

[22] S. Li, S. Chien, and P. I. Brånemark, "Heat shock-induced necrosis and apoptosis in osteoblasts," Journal of Orthopaedic Research, vol. 17, no. 6, pp. 891-899, 1999.

[23] C. Rouiller and G. Majno, "Morphologische und chemische untersuchung an knochen nach hitzeeinwirkung," Beiträge zur Pathologischen Anatomie und zur Allgemeinen Pathologie, vol. 113, pp. 100-120, 1953.

[24] H. H. J. De Vrind Wondergem and J. Haveman, "Hyperthermia-induced damage to rat sciatic nerve assessed in vivo with functional methods and with electrophysiology," Journal of Neuroscience Methods, vol. 45, no. 3, pp. 165-174, 1992.

[25] N. A. P. Franken, H. H. De Vrind, P. Sminia, J. Haveman, D. Troost, and D. Gonzalez Gonzalez, "Neurological complications after $434 \mathrm{MHz}$ microwave hyperthermia of the rat lumbar region including the spinal cord," International Journal of Radiation Biology, vol. 62, no. 2, pp. 229-238, 1992. 
[26] S. Uchiyama, K. Yashiro, H. Takahashi, and T. Homma, "An experimental study of spinal cord evoked potentials and histologic changes following spinal cord heating," Spine, vol. 14, no. 11, pp. 1215-1219, 1989. 

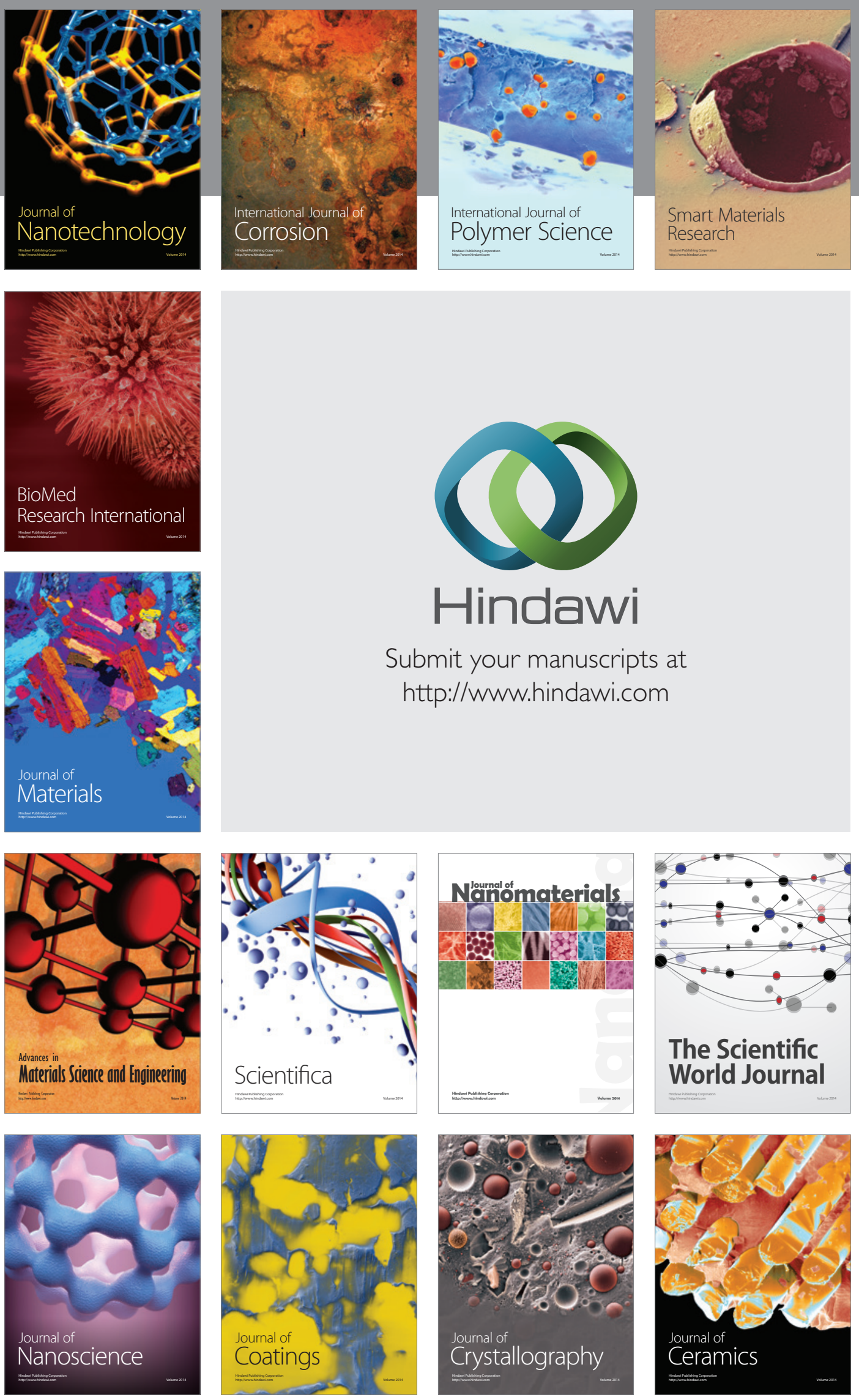

The Scientific World Journal

Submit your manuscripts at

http://www.hindawi.com

\section{World Journal}

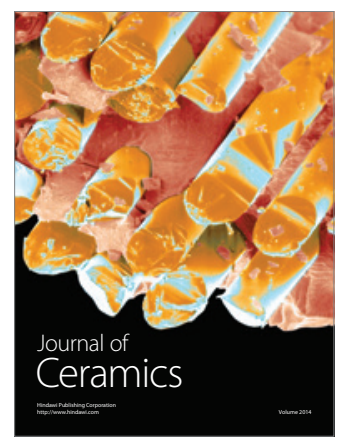

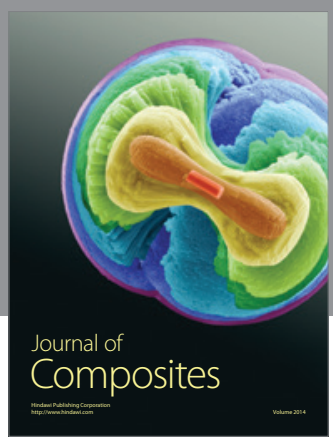
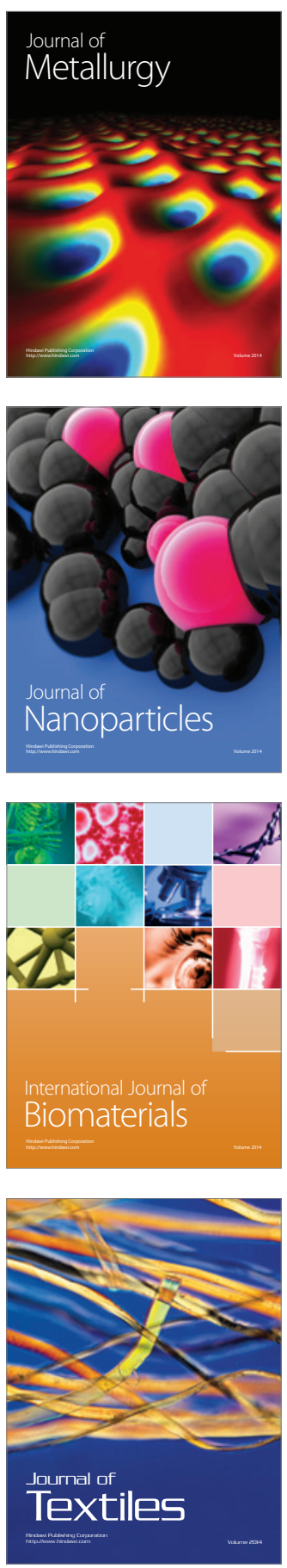